\title{
ESTUDO COMPARATIVO DA CARBONIZAÇÃO DE MADEIRA E ARROZ
}

\author{
Victória Beatriz Rontal Moisés \\ Vinicius Franca Oliveira ' \\ Cyro Takano' \\ Marcelo Breda Mourão ${ }^{1 *}$
}

\section{Resumo}

O trabalho apresenta resultados obtidos em estudos sobre carbonização de madeira e de arroz, que são biomassas que podem ser usadas como fonte de energia e são encontradas em diversos tipos de resíduos ou podem ser colhidas especificamente para esse uso. Amostras de madeira de eucalipto e de arroz foram carbonizadas em laboratório nas mesmas condições, nas temperaturas de $400^{\circ} \mathrm{C}, 60^{\circ} \mathrm{C}$ e $1000^{\circ} \mathrm{C}$. Os produtos obtidos foram caracterizados por microscopia eletrônica de varredura, difração de raios-X e dureza. Evidenciou-se microestruturas diferentes, sendo predominantemente celular para os carvões de madeira e globular para os carvões de arroz. A difração de raios- $X$ mostrou que ambos os materiais carbonizados são majoritariamente amorfos. A dureza do carvão de arroz é maior que a do carvão vegetal de madeira; essa diferença foi atribuída à estrutura obtida.

Palavras-chave: Biomassa; Carvão vegetal de madeira; Carvão vegetal de arroz.

\section{COMPARATIVE STUDY ON CARBONIZATION OF WOOD AND RICE}

\begin{abstract}
The work presents results obtained in studies on the carbonization of wood and rice, which are biomasses that can be used as an energy source and are found in several types of waste or can be harvested specifically for this use. Samples of eucalyptus and rice wood were carbonized in the laboratory under the same conditions, at temperatures of $400^{\circ} \mathrm{C}$, $600^{\circ} \mathrm{C}$ and $1000^{\circ} \mathrm{C}$. The products obtained were characterized by scanning electron microscopy, X-ray diffraction and hardness. Different microstructures were found, being predominantly cellular for wood coals and globular for rice coals. $\mathrm{X}$-ray diffraction showed that both carbonized materials are mostly amorphous. The hardness of rice charcoal is greater than that of wood charcoal; this difference was attributed to the obtained structure.
\end{abstract}

Keywords: Biomass; Wood charcoal; Rice charcoal.

\section{INTRODUÇÃO}

Um dos desafios no contexto do desenvolvimento sustentável é a redução das emissões de gases de efeito estufa. $O$ carvão fóssil, que responde por $41 \%$ da produção mundial de eletricidade, parece ser um obstáculo a essa meta. Outros materiais carbonosos de características energéticas e físico-químicas similares aparecem como possíveis substitutos do carvão fóssil na produção de energia elétrica e em outros processos industriais [I].

A biomassa, definida como toda matéria orgânica, seja de origem animal, vegetal ou micro-organismo, suscetível de ser transformada em energia, é uma das fontes energéticas mais antigas da humanidade. É a quarta maior fonte de combustíveis, atrás apenas de petróleo, carvão fóssil e gás natural, e possui características que a tornam atraente, como ser um recurso orgânico renovável com disponibilidade global e que pode ser produzido de forma sustentável, além de menor emissão de gases de efeito estufa e maior diversidade a ser explorada [2].

Biomassas são produzidas pela fotossíntese, que consiste na reação química que envolve luz, água e dióxido de carbono, tendo como produtos o oxigênio e açúcares, como a glicose. A reação I de fotossíntese é exibida a seguir [3].

$$
(\mathrm{Luz})+12 \mathrm{H}_{2} \mathrm{O}+6 \mathrm{CO}_{2} \rightarrow 6 \mathrm{O}_{2}+6 \mathrm{H}_{2} \mathrm{O}+\mathrm{C}_{6} \mathrm{H}_{12} \mathrm{O}_{6}
$$

'Departamento de Engenharia Metalúrgica e de Materiais, Escola Politécnica, Universidade de São Paulo - USP, São Paulo, SP, Brasil.

*Autor correspondente: mbmourao@usp.br

2I 76-I523 (C) 2020. Moisés et al. Publicado pela ABM. Este é um artigo publicado em acesso aberto (Open Access) sob a licença Creative Commons Attribution, que permite uso, distribuição e reprodução em qualquer meio, sem restrições desde que o trabalho original seja corretamente citado. 
A glicose é um monossacarídeo de 6 carbonos, e uma das principais fontes energéticas dos organismos vivos [4]. As moléculas de glicose possuem duas formas alotrópicas, uma é acíclica e a outra é cíclica. Nos amidos é observada a forma cíclica da alfaglicose. A alfaglicose e a betaglicose são duas formas da glicose que se diferenciam uma da outra pela posição do grupo $\mathrm{OH}$. A alfaglicose de forma cíclica dá origem a amilose e a amilopectina, constituintes do amido. Já a betaglicose, também de forma cíclica, dá origem a celulose, macromolécula que forma a parede celular das plantas.

A biomassa tem duas grandes famílias de produtos vegetais, a dos vegetais lenhosos e a dos vegetais não-lenhosos [5]. Os vegetais lenhosos, basicamente a madeira, são constituídos por celulose, hemicelulose e lignina. De um modo geral, as espécies de eucalipto têm a composição média em peso de $50 \%$ de celulose, $24 \%$ de hemicelulose e $23 \%$ de lignina na madeira seca [6]. Os vegetais não-lenhosos são classificados de acordo com o principal componente de sua reserva energética, que pode ser a celulose (vegetais não-lenhosos celulósicos, como capim elefante), o amido (vegetais não-lenhosos amiláceos, como milho, batata, arroz, mandioca, etc), sacarose (vegetais sacarídeos, como cana de açúcar) e vegetais aquáticos (algas).

O principal uso de vegetais amiláceos para produção de energia envolve processos de hidrólise-fermentação para produção de etanol, como é o caso do milho. Ocorre que uma grande fonte de biomassa são os resíduos agricolas, urbanos e industriais, nos quais há misturas dos vegetais em proporções muito diversas. A aplicação energética destes resíduos pode seguir diferentes rotas, desde combustão direta até produção de biogás ou etanol.

A pirólise para obtenção de carvão vegetal pode ser uma alternativa viável para resíduos agrícolas e urbanos. Estes tipos de resíduos podem conter vegetais lenhosos e não-lenhosos, dos quais os amiláceos podem ser parte significativa. Assim, torna-se relevante o estudo da pirólise de vegetais amiláceos e de seu produto, área menos estudada que a pirólise da madeira para obtenção de carvão vegetal.

O amido é o único polissacarídeo encontrado em todos os tecidos vegetais conhecidos. É formado por pequenas unidades, chamadas de grânulos. Há semelhanças com os grãos que compõem materiais metálicos, por exemplo, pois essas estruturas apresentam nucleação e crescimento.

No caso do arroz cru, que contém de $12,2 \%$ a $13,2 \%$ de umidade, a concentração em massa de amido vai de 77,5 a $78,9 \%$, de lipídios varia na faixa de 0,3 a I,9\% e a de proteínas é de cerca de 7,5\%. Estas pequenas variações dependem do tipo de arroz, se integral, tipo I ou tipo 2 [7]. A quantidade de amilose também varia entre diferentes tipos de arroz [8].

Além de fatores como a relação entre as moléculas de amilose e amilopectina e capacidade de inchamento na presença de água, as propriedades do amido também podem ser diferenciadas através da observação do tamanho e da estrutura cristalina dos seus grânulos [9].
As propriedades do amido sofrem grande influência quando o mesmo está em presença de água (cozido ou não). $O$ amido, quando em meio aquoso absorve água. Quando a mesma é aquecida até $58^{\circ} \mathrm{C}$, o amido absorve mais umidade e incha, variando de acordo com o tamanho dos grânulos e proporção entre as moléculas que o compõem. Aumentando a temperatura gradativamente, começa a haver liberação de cadeias de amilose e amilopectina em meio aquoso, ocorrendo novamente a absorção da água e a formação de um gel. A viscosidade desse produto cresce até um patamar máximo, a partir do qual qualquer energia fornecida ao sistema, seja sob forma de calor ou agitação, resulta na diminuição da viscosidade do gel. Esse processo se chama gelatinização, que consiste na formação do gel em meio aquoso e com aquecimento. A temperatura de gelatinização é aquela na qual ocorre o desaparecimento dos cristais de amido [ $10,1 \mathrm{I}]$.O processo de carbonização, ou pirólise, é realizado a temperaturas acima de $300^{\circ} \mathrm{C} \mathrm{em}$ atmosfera inerte, e é responsável pela remoção da umidade $e$ dos materiais voláteis tendo como produto um resíduo sólido (carvão) e vapores condensáveis e não condensáveis [12].

O mecanismo exato e as reações de decomposição da biomassa nos produtos líquidos, sólidos e gasosos não são totalmente dominados devido à complexidade do processo, a grande variação de produtos intermediários e a diferença na composição da biomassa utilizada no processo. $O$ que se sabe é que os fatores que mais influenciam o rendimento do produto final são: temperatura de pirólise, taxa de aquecimento, tempo de residência no forno e pressão do sistema, tamanhos de partícula, composição (concentração de cinzas, umidade) e densidade [ 13$]$.

O arroz é um vegetal amiláceo; o arroz tipo I comercial tem composição média, em base seca e sem cinzas, de $91,3 \%$ de carboidratos, $8,3 \%$ de proteínas e $0,4 \%$ de lipídios. Naturalmente possui em torno de $13 \%$ de umidade e $0,5 \%$ de cinzas, cujos principais constituintes são fósforo e potássio [7].

Este trabalho pretende complementar estudos de carbonização da madeira realizados nos últimos anos [14-19], introduzindo outra fonte importante de biomassa, abundante em resíduos agrícolas e urbanos. Desta forma, o objetivo é apresentar um estudo comparativo da carbonização de madeira e de arroz, sendo este último o vegetal amiláceo escolhido.

\section{MATERIAIS E MÉTODOS}

\section{I Materiais}

Os materiais de partida para este trabalho foram amostras de Eucaliptus Saligna como fonte de madeira e arroz agulhinha tipo I, adquirido em supermercado.

A Tabela I apresenta a análise imediata em base seca destes materiais. 
Tabela I. Análise imediata da madeira de eucalipto e de arroz cru, base seca

\begin{tabular}{lccc}
\hline & Carbono fixo, $\%$ & Matéria volátil, \% & Cinzas, $\%$ \\
\hline Madeira (Eucalipto) & 22,2 & 76,5 & 1,3 \\
Arroz cru & 13,4 & 84,5 & 1,7 \\
\hline
\end{tabular}

A determinação do teor de matéria volátil foi feita, após secagem dos materiais, por aquecimento de amostras a $950^{\circ} \mathrm{C}$ sob atmosfera de argônio até peso constante. $\mathrm{O}$ teor de cinzas foi determinado por queima controlada das amostras, por aquecimento em forno elétrico a $950^{\circ} \mathrm{C}$ ao ar por 24 horas.

A Figura I apresenta Análise Termogravimétrica (TG) de madeira de eucalipto enquanto a Figura 2 apresenta a TG de arroz cru, ambas realizadas utilizando equipamento da marca STA Netzsch, sob gás nitrogênio.

Pode-se observar que, enquanto para o eucalipto a perda de massa ocorre em uma faixa ampla de temperaturas, com início em torno de $250^{\circ} \mathrm{C}$ e fim próximo de $500^{\circ} \mathrm{C}$, para $\mathrm{o}$ arroz a perda de massa ocorre quase toda (acima de $90 \%$ ) a uma temperatura constante, no caso, de $285^{\circ} \mathrm{C}$. Este fenômeno é um reflexo das diferentes substâncias principais que formam um e outro material: celulose, hemiceulose e lignina no caso de eucalipto, amilopectina e amilose no caso do arroz.

\subsection{Métodos}

A carbonização da madeira e do arroz foi feita de acordo com o procedimento a seguir: amostras de madeira de Eucaliptus Saligna, de formato cúbico com aproximadamente $0,02 \mathrm{~m}$ de lado, e arroz cru tipo I (agulha) foram carbonizados nas temperaturas de 400,600 e $1000^{\circ} \mathrm{C}$. Para cada tipo de material, três cadinhos (de carbeto de silicio) contendo em torno de $200 \mathrm{~g}$ de material eram colocados no forno pré-aquecido a $400^{\circ} \mathrm{C}$. Após 3 horas, um dos cadinhos era retirado do forno e resfriado sob fluxo de nitrogênio. Os cadinhos remanescentes foram aquecidos a $600^{\circ} \mathrm{C}$ e mantidos nesta temperatura por I hora. Depois disso, outro cadinho era retirado o remanescente aquecido a $1000^{\circ} \mathrm{C}$ por I hora. Após o resfriamento, as amostras foram caracterizadas e comparadas. O forno utilizado foi forno elétrico de resistências de carbeto de silício marca Lindberg-Blue.

A caracterização das amostras foi feita através de análises de difração de raios- $X$, microscopia eletrônica de varredura e por determinação da dureza Janka.

A preparação para microscopia de varredura incialmente consistiu no embutimento a frio das amostras utilizando resina transparente de cura de 10 horas. Prosseguiu-se com lixamento mecânico com baixa força e, para evitar a perda de material, não foi realizada a etapa de polimento. Para tornar as amostras condutoras e obter imagens com boa resolução, foi utilizada uma máquina metalizadora de deposição de íons metálicos de ouro. $O$ equipamento é da marca BALZERS modelo SCD 050. O microscópio eletrônico de varredura utilizado foi o INSPECT F50.

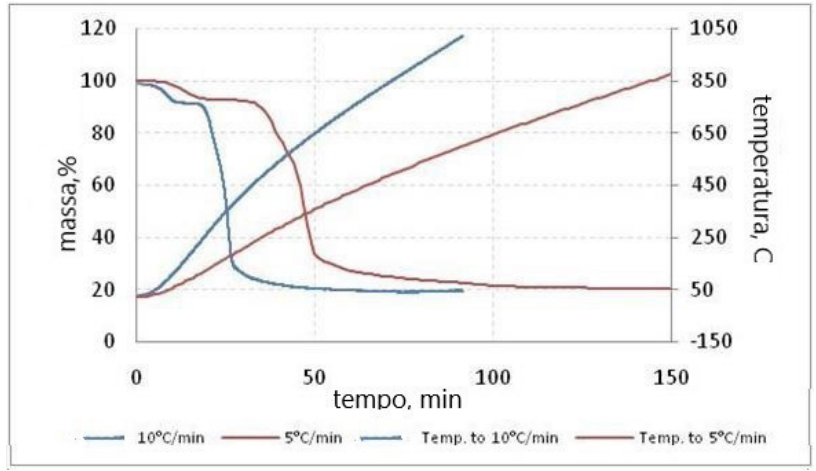

Figura I. Análise Termogravimétrica de madeira de eucalipto.

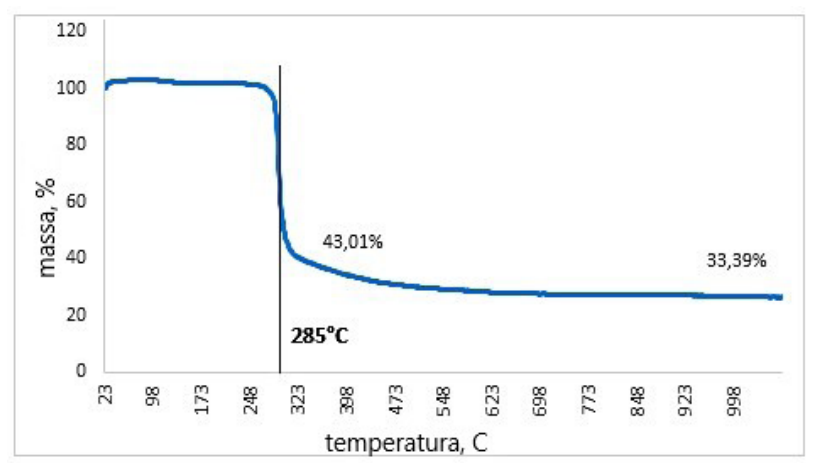

Figura 2. Análise Termogravimétrica de arroz cru.

A difração de raios- $X$ foi realizada em equipamento DRX 02 - Philips - X'Pert PRO PW 3040/00.

O ensaio de obtenção de propriedades mecânicas consistiu na adaptação do ensaio de dureza Janka realizado para madeira e normalizado pela norma NBR 7 I 90 . Tal ensaio consistiu em, através de uma máquina de ensaio universal da marca KRATOS, pressionar uma semiesfera de aço de $2,5 \mathrm{~mm}$ de diâmetro sobre o corpo de prova cúbico de aresta de $2 \mathrm{~cm}$ em análise. Foi necessário realizar uma adaptação para utilizar a semiesfera na máquina universal [20]. Para realização dos ensaios de dureza Janka, utilizou-se as amostras cúbicas de $2 \mathrm{~cm}$ de aresta de carvão vegetal (retiradas da porção mais externa do raio da madeira) e de carvão de amido. A dureza Janka mede a força necessária para inserir uma esfera de aço de II,28 milímetros de diâmetro a meio caminho em uma amostra de madeira. Para o carvão vegetal, a medida foi realizada paralelamente ao eixo dos grãos (é chamada de "dureza final" ou "end hardness"). As adaptações que diferiram da norma NBR 7/90 referem-se à mudança da dimensão do corpo de prova, já que o estabelecido pela norma seria maior do que a dimensão máxima que poderia ser colocada no cadinho para efetuar a carbonização. 


\section{RESULTADOS E DISCUSSÃO}

\section{I Microscopia Eletrônica de Varredura (MEV)}

A Figura 3 apresenta imagens de Microscopia Eletrônica de Varredura de amostras de carvão obtido por carbonização e madeira de eucalipto. Pode-se observar que o carvão vegetal da madeira apresenta uma microestrutura celular característica.

A Figura 4 apresenta microscopia eletrônica de varredura de arroz cru (esquerda) e de arroz carbonizado a $400^{\circ} \mathrm{C}$.

Observa-se a estrutura granular do arroz cru, formado por grãos de amido, e a estrutura resultante da carbonização, quando o amido perde sua estrutura granular e há formação de estrutura porosa e coalescimento do material formado. Durante a carbonização de madeira, a estrutura inicial sofre transformações, mas mantém a configuração estrutural relativamente preservada até o fim do processo. Já no caso da carbonização de materiais amiláceos, como o arroz, a estrutura granular inicial é destruída durante o aquecimento com o amolecimento e fusão parcial do material.

A Figura 5 a seguir reúne três imagens com mesmo aumento de amostras de arroz obtidas pela microscopia eletrônica de varredura. Estão apresentadas as amostras $\mathrm{A}, \mathrm{B}$ e $\mathrm{C}$, carbonizadas a $400^{\circ} \mathrm{C}, 600^{\circ} \mathrm{C}$ e $1000^{\circ} \mathrm{C}$, respectivamente.

Foi possível observar que não houve mudanças significativas visíveis na sequência de aumento de temperatura de carbonização. Porém, vale dizer que a distribuição dos poros apresentou um padrão. Nas três temperaturas, os poros no centro do grão apresentam diâmetros superiores aos encontrados nas extremidades.

\subsection{Difração de Raios-X}

A Figura 6 mostra a comparação dos difratogramas resultantes de amostras de arroz carbonizado nas temperaturas de $400^{\circ} \mathrm{C}, 600^{\circ} \mathrm{C}$ e $1000^{\circ} \mathrm{C}$, com o objetivo de comparar a interferência da temperatura final de carbonização com
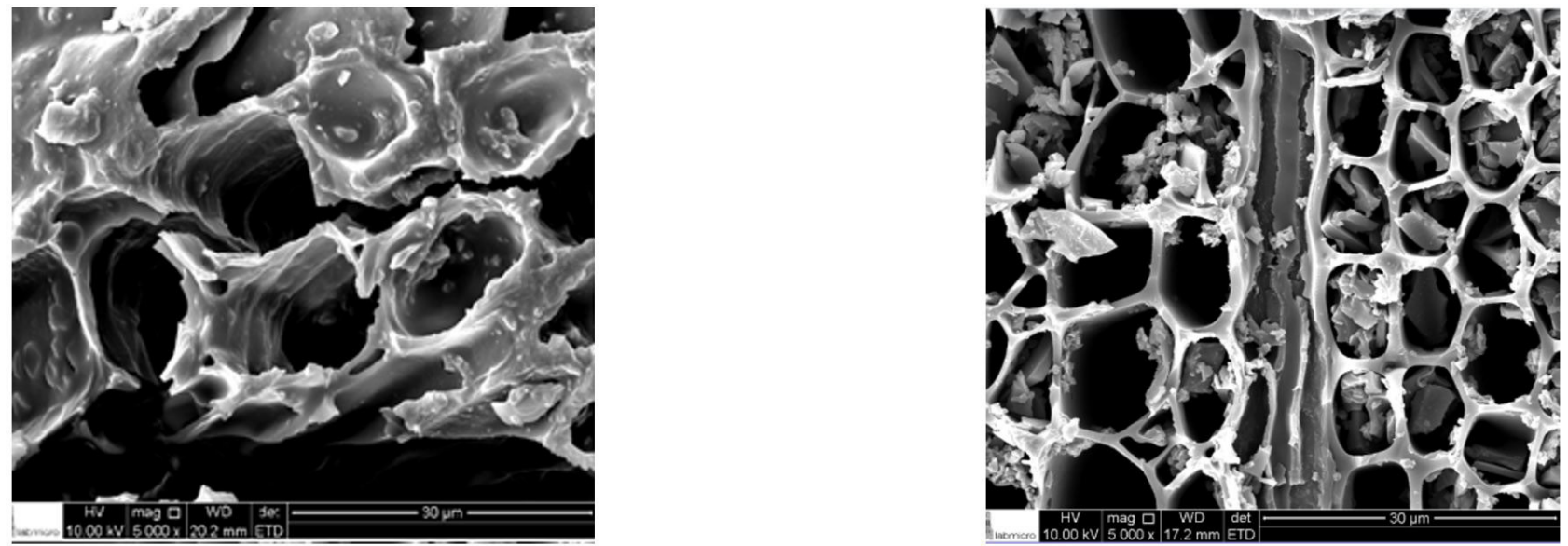

Figura 3. Microscopia eletrônica de varredura do carvão vegetal obtido após carbonização a $400^{\circ} \mathrm{C}$ (esquerda) e a $600^{\circ} \mathrm{C}$ (direita).
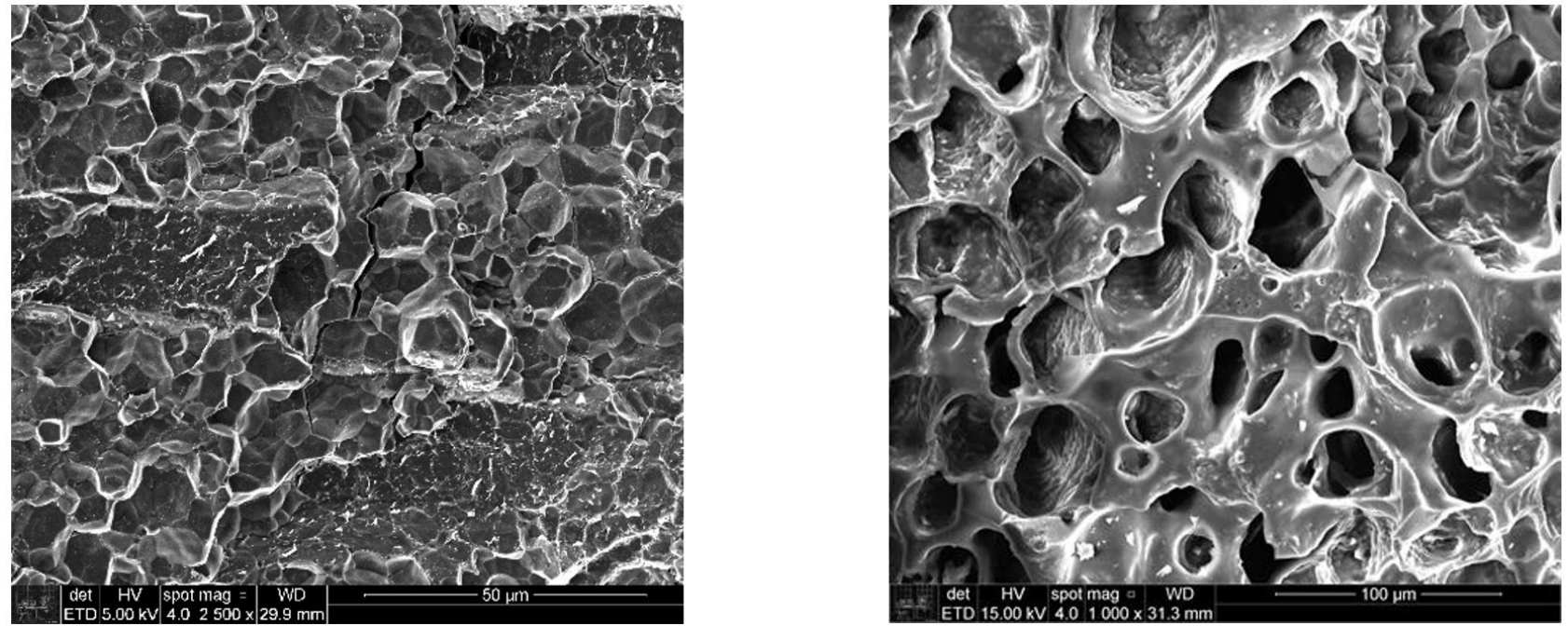

Figura 4. Microscopia eletrônica de varredura de arroz cru (esquerda) e de arroz carbonizado a $400^{\circ} \mathrm{C}$ (direita). 


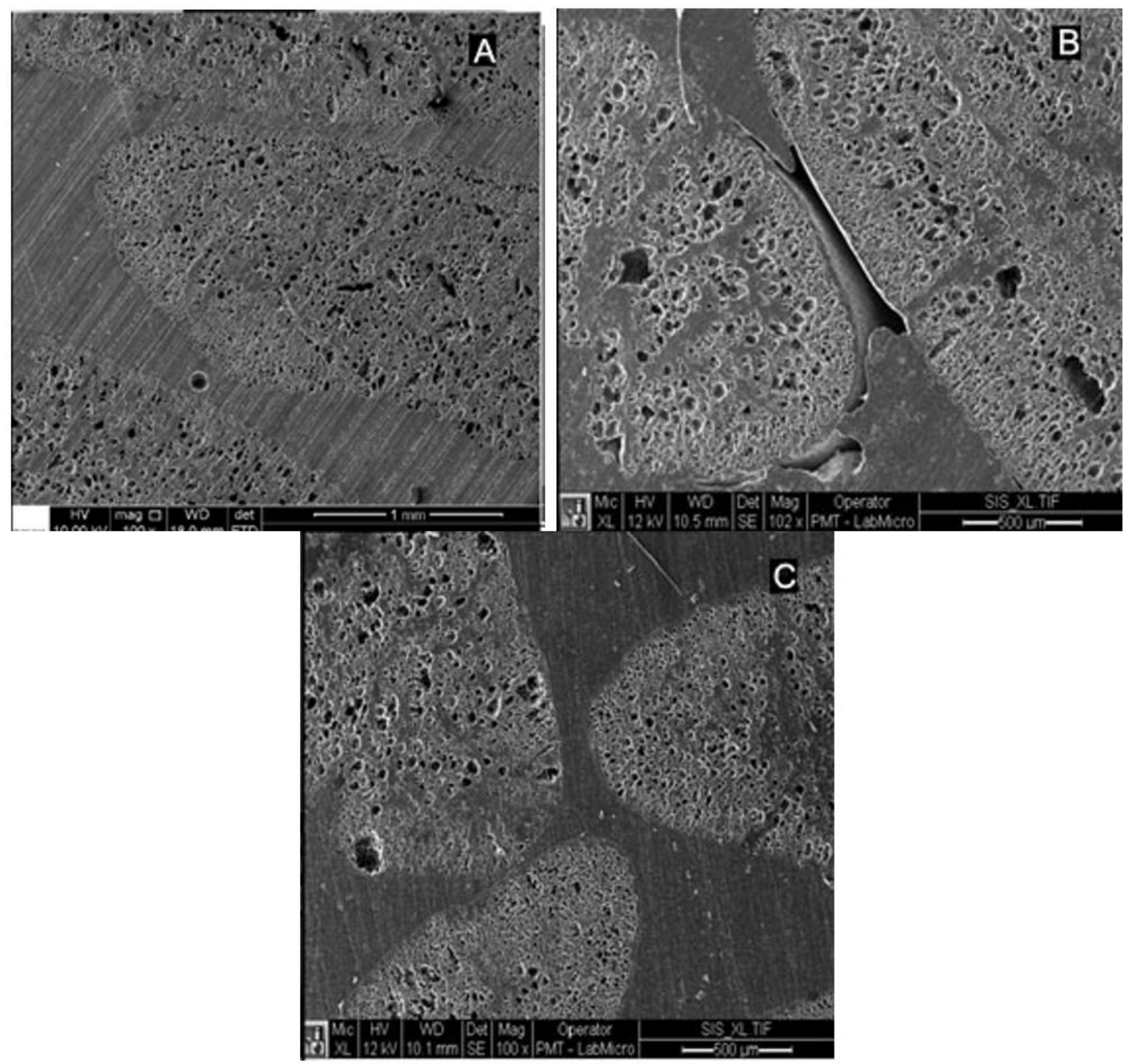

Figura 5. Imagens de microscopia eletrônica de varredura de arroz carbonizado a $400^{\circ} \mathrm{C}(\mathrm{A}), 600^{\circ} \mathrm{C}(\mathrm{B})$ e $1000^{\circ} \mathrm{C}(\mathrm{C})$.

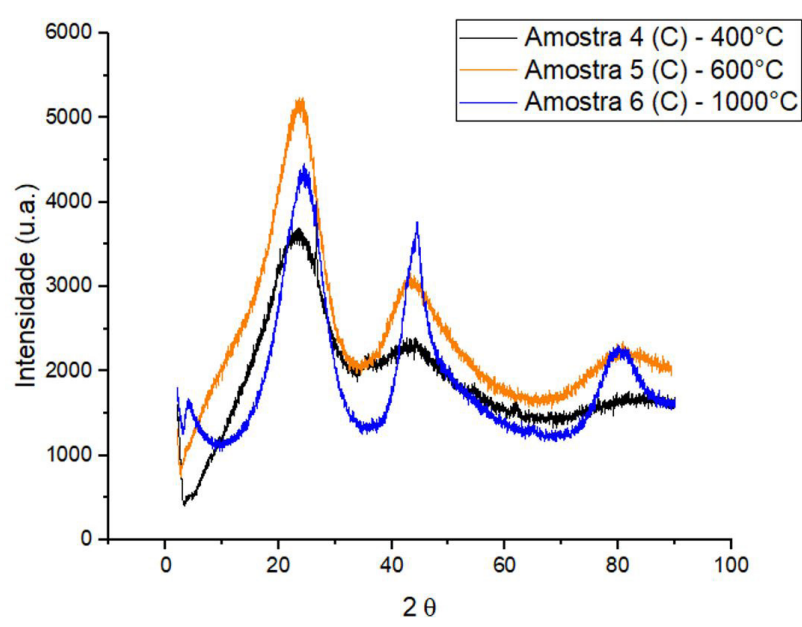

Figura 6. Comparação dos difratogramas resultantes de amostras de arroz carbonizado nas temperaturas de $400^{\circ} \mathrm{C}, 600^{\circ} \mathrm{C}$ e $1000^{\circ} \mathrm{C}$. amostras que foram igualmente preparadas. A amostra 6 , carbonizada a $1000^{\circ} \mathrm{C}$, apresentou uma fase cristalina distinta em $2 \theta$ de $5.1^{\circ}$, além de apresentar picos de maior intensidade. De forma análoga, a amostra $5\left(600^{\circ} \mathrm{C}\right)$ possui picos mais intensos que os da amostra $4\left(400^{\circ} \mathrm{C}\right)$, inclusive maior intensidade na banda (002) em comparação ao valor apresentado pela amostra 6. Aparentemente há um aumento da cristalização em função da temperatura, fenômeno amplamente observado na literatura, como relatado por diversos pesquisadores [2I-23].

A Figura 7 mostra uma comparação entre as distintas fontes de biomassa carbonizadas a $400^{\circ} \mathrm{C}$ e a $1000^{\circ} \mathrm{C}$. No caso, é visível que a amostra de arroz submetida a mesma condição apresentou pico (002) mais largo que o da amostra de eucalipto. Este fato é uma indicação que os cristalitos do carvão de arroz são menores que aqueles do carvão de madeira, de acordo com a equação de Scherrer [24]. 
A Figura 8 apresenta os resultados da análise de difração de Raios-X de carvões de madeira e de arroz após a carbonização, juntamente com os resultados para grafite pura, cujo pico principal ocorre a $26^{\circ}$, como visto anteriormente. Pode-se observar para ambos os materiais a ocorrência de um pico de intensidade principal, que aproximadamente coincide com o pico principal da grafita pura, com algum desvio e com intensidade muito menor. Esta é uma indicação de que ambos os materiais, apesar de apresentarem diferenças no grau de cristalinidade, são principalmente amorfos.

Os resultados dos ensaios de difração de raios $\mathrm{X}$ revelam que todas as amostras, tanto de arroz como de eucalipto carbonizados a diferentes temperaturas, apresentam perfis de picos que refletem uma grande proporção de materiais desordenados na forma de carbono amorfo. Entretanto, o padrão dos picos mostra que todos os carvões contêm algumas estruturas semelhantes à grafite (carbono cristalino) indicado pela presença de um pico em torno de $26^{\circ}$ que corresponde ao plano (002) da grafita, outro próximo de $42^{\circ}$, correspondente ao plano ( 100$)$ e um terceiro em torno de $54^{\circ}$ correspondendo ao plano (004) da grafita; assim como observado por Sonibare et al. [2I]

\subsection{Dureza Janka}

A Figura 9 apresenta a Dureza Janka para carvão de madeira e de arroz em função da temperatura de carbonização. Pode-se observar que a dureza do carvão de
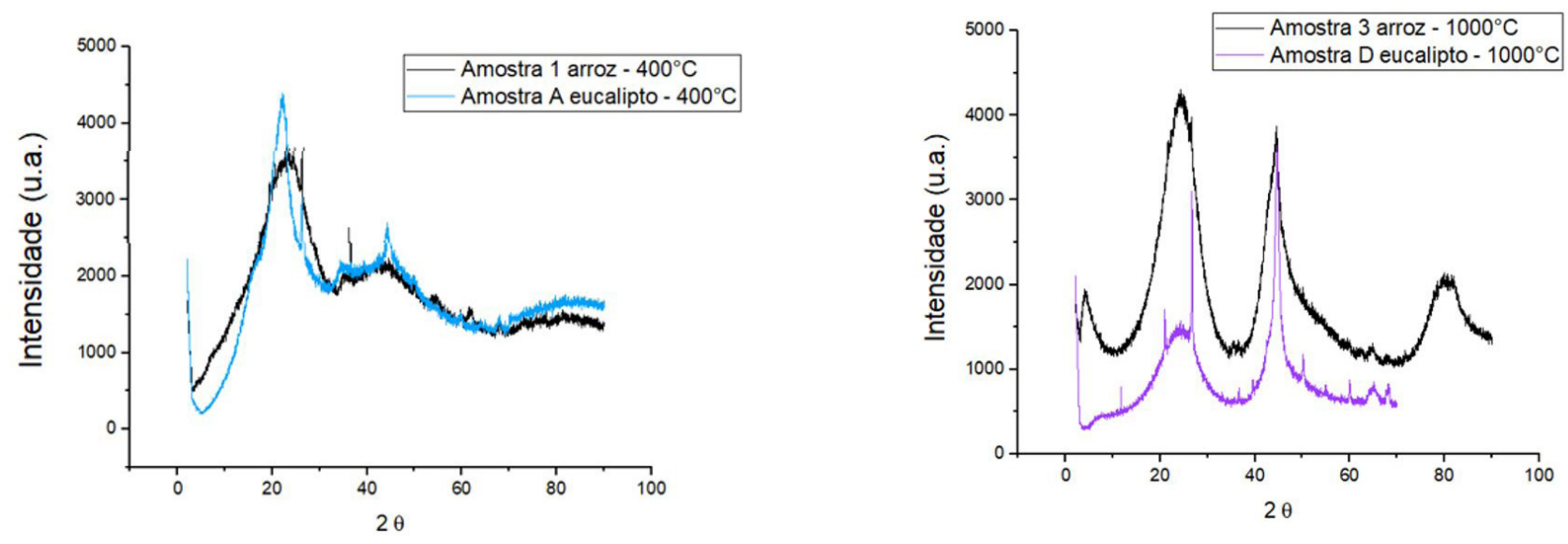

Figura 7. Difratogramas de arroz e de eucalipto carbonizados a $400^{\circ} \mathrm{C}$ (esquerda) e a $1000^{\circ} \mathrm{C}$ (direita).
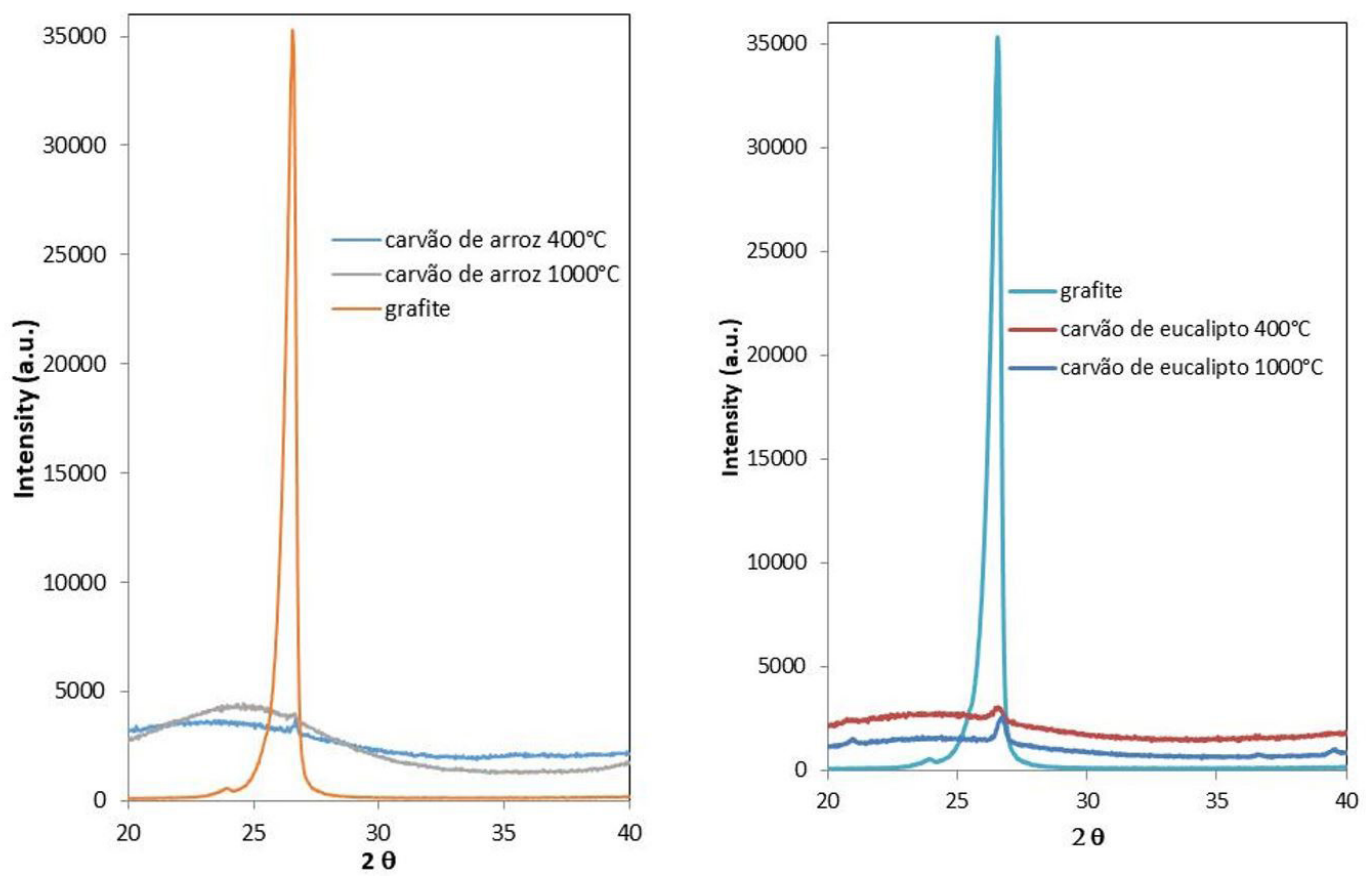

Figura 8. Comparação do espectro de difração de raios-X de grafite pura e carvões de madeira (direita) e arroz (esquerda) carbonizados a $400^{\circ} \mathrm{C}$ e $1000^{\circ} \mathrm{C}$. 


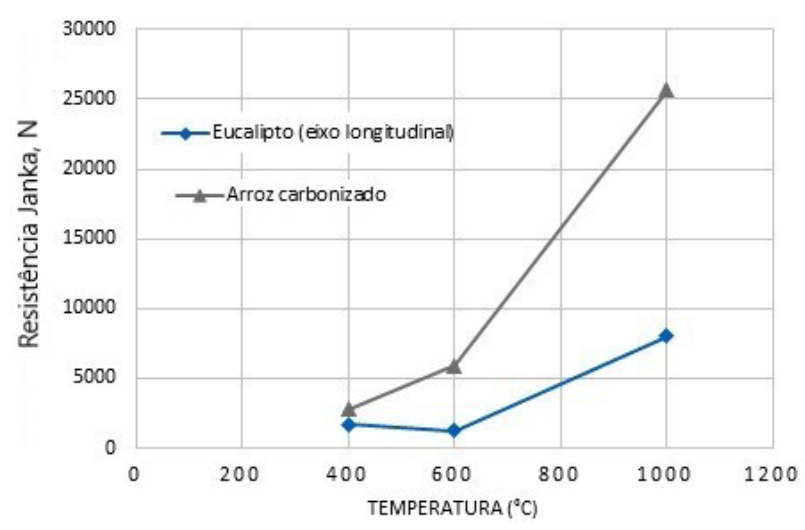

Figura 9. Dureza Janka dos carvões de madeira e arroz em função da temperatura de carbonização.

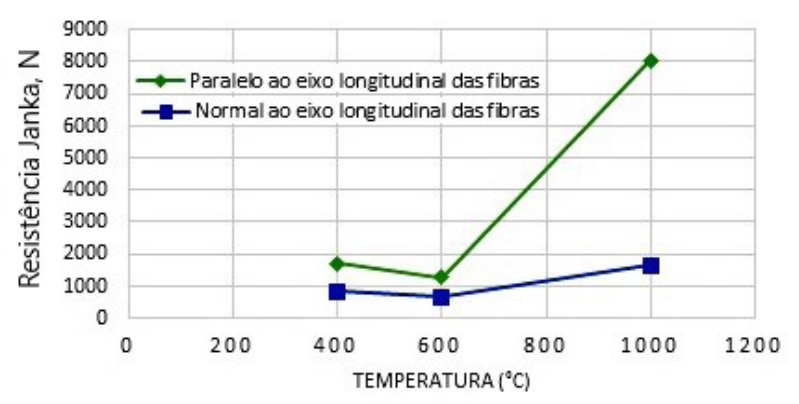

Figura 10. Dureza Janka dos carvões de madeira em função da direção das fibras.

arroz é maior que a do carvão de madeira e que quando se aumenta a temperatura de carbonização a dureza aumenta como também aumenta a diferença entre os dois tipos de carvão. Observa-se para os carvões de eucalipto (Figura 10) que a dureza varia com a direção das fibras, sendo maior quando medida em direção paralela ao eixo longitudinal das fibras. Isto evidencia o caráter anisotrópico do carvão de madeira, e não foi observado no carvão de arroz.

A microscopia eletrônica de varredura revelou diferenças significativas entre as estruturas dos carvões obtidos ou a partir de arroz ou a partir de eucalipto. Além disto, a difração de raios- $X$ mostrou que o grau de cristalinidade dos dois tipos de carvão é semelhante e bem baixo em relação ao da grafite, Deste modo, a diferença de comportamento mecânico dos dois tipos de carvão pode ser atribuída a diferenças em sua estrutura, que é homogênea para o arroz e fibrosa e anisotrópica no caso da madeira, e não ao grau de cristalinidade.

\section{CONCLUSÕES}

Os carvões obtidos pela carbonização da madeira e do arroz a diferentes temperaturas foram caracterizados por microscopia eletrônica de varredura, análise de difração de raios $\mathrm{X}$ e dureza. Foi demonstrado que o carvão de arroz apresenta maior dureza que o carvão de eucalipto e uma estrutura homogênea, enquanto o carvão vegetal apresenta estrutura celular e anisotropia em relação a dureza. A análise de difração de raios $X$ mostrou que ambos os carvões são principalmente amorfos. Desta maneira, pode-se afirmar que a principal característica que determina o comportamento mecânico entre os dois tipos de carvão é estrutural, consequência dos diferentes fenômenos que ocorrem na carbonização de matérias amiláceos e aqueles celulósicos.

\section{REFERÊNCIAS}

I International Energy Agency - IEA. World energy balance overview. Paris; 2017.

2 Vieira GEG, Nunes AP, Teixeira LF, Colen AGN. Biomassa: uma visão dos processos de pirólise. Revista Liberato. 20I4; I5(24): 105-2I2.

3 Souza JSI. Amido. In: Sousa JSI, Peixoto AM, Toledo FF, editores. Enciclopédia agricola brasileira. Vol. I A-B. São Paulo: EDUSP; 1995.

4 Cui SW. Food carbohydrates. Boca Raton: Taylor \& Francis; 2005. http://dx.doi.org/10.1201/9780203485286.

5 Brasil. Balanço energético nacional. Brasília: Ministério de Minas e Energia; 2015.

6 Valente OF, Ferreira AR. Carbonização de madeira. In: Masuda H. Carvão e coque aplicados à metalurgia. 2. ed. Vol. 2. São Paulo: ABM; 1983.

7 Universidade Estadual de Campinas - UNICAMP. Tabela Brasileira de Composição de Alimentos (TACO). 4. ed. Campinas: NEPA; 2011 .

8 Lin Q, Xiao H, Li L, Yu F, Tian W. Studies on the pasting and rheology of rice starch with different protein residual. IFIP Advances in Information and Communication Technology. 2010;317:407-4I9.

9 Cauvain PS, Young SL. Tecnologia da panificação. 2. ed. São Paulo: Manole; 1999.

10 Walter M, Marchezan E, Avila LA. Arroz: composição e características nutricionais. Ciência Rural. 2008;38(4):I I84I 192. http://dx.doi.org// 0.1590/S0 I03-84782008000400049. 
I I Ratnayake WS, Jackson DS. A new insight into the gelatinization process of native starches. Carbohydrate Polymers. 2007;67(4):5 I I-529. http://dx.doi.org/I0.1016/j.carbpol.2006.06.025.

12 Antal MJ, Grønli M. The art, science, and technology of charcoal production. Industrial \& Engineering Chemistry Research. 2003;42(8):1619-1640. http://dx.doi.org/10.1021/ie0207919.

13 Taylor P, editor. The biochar revolution: transforming agriculture and environment. Queensland: NewLife Publishing, 2010.

14 Cruz AJ, Toledo NN, Takano C, Mourão MB, Salvagnini WM. Carvão vegetal: uma proposta de produção sustentável. Metalurgia e Materiais. 2009;65:268-27I.

I5 Ribeiro TR, Naso PG, Takano C, Mourão MB. Análise do processo de produção de carvão vegetal para siderurgia. In: Anais do $41^{\circ}$ Seminário de Redução de Minério de Ferro; 20II; Vila Velha. Vol. I. São Paulo: ABM; 20II. p. 663-674.

16 Narita CY, Cardona LMV, Mourão MB, Takano C. Efeito das condições de carbonização da madeira nas características redutoras do carvão vegetal. In: Anais do $41^{\circ}$ Seminário de Redução de Minério de Ferro; 20II; Vila Velha. Vol. I. São Paulo: ABM; 20I I. p. 224-233.

17 Mourão MB, Cardona LMV, Takano C. Pre-drying Eucalyptus saligna for carbonization. In: Kvithyld A, Meskers C, Kirchain R, Krumdick G, Mishra B, Reuter M, et al. REWAS 2013: enabling materials resource sustainability. Cham: Springer; 2016. p. 36-42.

18 Kurauchi MHN, Takano C, Narita CY, Mourão MB. Lab scale test of charcoal compression strength: a new approach. In: Anais do 44 Seminário de Redução de Minério de Ferro e Matérias-Primas; 20I4; Belo Horizonte. São Paulo: ABM; 2014.

19 Cardona LMV, Narita CY, Takano C, Mourão MB. Characterisation of coal-charcoal composite biocoke as a sustainable alternative for ironmaking. Canadian Metallurgical Quarterly. 20I7;I(2):I-9. http://dx.doi.org/10.1080/00 084433.2017.1299342.

20 Associação Brasileira de Normas Técnicas - ABNT. NBR 7190: Projeto de estruturas de madeira. Rio de Janeiro; 1997.

2I Sonibare OO, Haeger T, Foley SF. Structural characterization of Nigerian coals by X-ray diffraction, Raman and FTIR spectroscopy. Energy. 2010;35(I2):5347-5353. http://dx.doi.org/I0.1016/j.energy.2010.07.025.

22 Kercher AK, Nagle DC. Microstructural evolution during charcoal carbonization by $X$-ray diffraction analysis. Carbon. 2003;4I(I):15-27. http://dx.doi.org/I0.1016/S0008-6223(02)0026I-0.

23 Zickler GA, Smarsly B, Gierlinger N, Peterlik H, Paris O. A reconsideration of the relationship between the crystallite size La of carbons determined by X-ray diffraction and Raman spectroscopy. Carbon. 2006;44(I5):32393246. http://dx.doi.org/10.1016/j.carbon.2006.06.029.

24 Cullity BD. Elements of X-ray diffraction. Massachusetts: Addison-Wesley; 1978.

Recebido em: 27 Nov. 2018

Aceito em: 24 Ago. 2020 